\title{
Determination of Carbofuran Residue in the Samples of Sugarcane (Sacharum officinarum L) and Soil of Sugarcane Field
}

\author{
K. H. Kabir ${ }^{1 *}$, M. Abdullah ${ }^{2}$, M. D. H. Prodhan ${ }^{1}$, M. S. Ahmed ${ }^{1}$ and M. N. Alam ${ }^{2}$ \\ ${ }^{1}$ Pesticide Research and Environmental Toxicology Section, Entomology Division, \\ Bangladesh Agricultural Research Institute, Gazipur-1701, Bangladesh \\ ${ }^{2}$ Entomology Division, Bangladesh Sugarcane Research Institute, Ishurdi, Pabna, Bangladesh \\ *Corresponding author: Email: dalower.ento@bari.gov.bd
}

Received: 15 November 2007 Accepted: 27 December 2007

\begin{abstract}
An experiment was carried out at the Regional Sugarcane Research Station, Gazipur in which carbofuran (2 kg AI/ha) was applied in sugarcane field to document the level of carbofuran residue left in soil and plant samples after different days of application (DAA). Plant and soil samples were analyzed by using GCMS-EI. Carbofuran residues were found even at 90 DAA both in soil and plant. In case of soil, the amount of carbofuran residues were 24.84, 3.32, 2.12, 0.59, 0.035, 0.02 and 0.005 ppm at $0,3,7,15,30,60$ and 90 DAA, respectively. In case of plant samples, the lower residue $(0.0035$ ppm) was observed at 0 DAA compared to those at 3 DAA $(0.075 \mathrm{ppm}), 7 \mathrm{DAA}(0.035 \mathrm{ppm})$ and 15 DAA $(0.015 \mathrm{ppm})$. At 60 and 90 DAA, residues were the same $(0.002 \mathrm{ppm})$ while at $30 \mathrm{DAA}$ it was $0.0025 \mathrm{ppm}$. The highest level of carbofuran residue $(0.075 \mathrm{ppm})$ in plant samples was found at 3 DAA which is lower than FAO/WHO recommended MRL $(0.1 \mathrm{mg} / \mathrm{kg}$ crop).
\end{abstract}

Keywords: Sugarcane, carbofuran, MRL

\section{Introduction}

Carbofuran (2, 3-dihydro-2, 2-dimethyl-7benzofuranyl N-methylcarbamate) was developed by FMC as contact and systemic insecticide in 1969, which is also effective as acaricide and nematicide. Carbofuran has a high acute oral and low dermal toxicity. It is reported to be the most effective insecticide in controlling the major rice pests particularly brown planthopper (Nilaparvata lugens Stal) when broadcast to the flooded rice fields as granules or when incorporated to the root zone in paper or gelatin capsules (IRRI, 1975).

In Bangladesh, more than 37,712.20 tons of formulated products of pesticide was sold during
2007 of which $14,849.56$ tons were carbofuran (Anon, 2007). Carbofuran is generally used for controlling the insect pests of different crops like rice, jute, sugarcane etc. The application rate of carbofuran is $40 \mathrm{~kg} / \mathrm{ha}$ in sugarcane (Anon, 1996). Side-effect of carbofuran applications was observed in frogs and birds. Some birds that consumed spilled granules died immediately. Carbofuran applications, as practiced in the region, have cause dramatic effects on many non target organisms. Its use is hazardous to wildlife, and it severely reduces the significance of irrigated rice fields as a feeding habitat for birds, including waders, and other insectivorous organisms (Mullie et al., 2005). 
Carbofuran is rapidly taken up by plants through the roots from soil, water or nutrient solution and is translocated mainly into the leaves (Ashworth and Sheets, 1972). The rapidity of carbofuran degradation differed in the various plant species and the main metabolite was identified as 3hydroxycarbofuran (Talekar et al., 1977a) .There are several studies on carbofuran degradation after application. Various factors like temperature, water content, $\mathrm{pH}$ etc influence its degradation (Stanovick, 1968; Getzin, 1973; Caro et al., 1973 and Talekar et al., 1977b). Talekar et al. (1977b) noted that in subtropical soils, carbofuran was more persistent during the dry and relatively cooler autumn and winter months than in summer. After ten months, only $0.6 \%$ of the residues present initially could be recovered as parent compound.

Presently, the farmers are totally dependent on the use of insecticides to control insect pests. All pesticides compounds potentially pose environmental hazards as they are chemically tailored to be toxic. While causing lethal effect to target pests, these chemicals may also evoke acute and chronic toxic effect to non - target organisms. An intensified use of insecticides can cause a serious public health hazard especially in the form of residues in food (Mansingh. et al., 1996). Maclntyre et al. (1989) reported that low level exposure of food products containing insecticide residues over time might cause cancer, teratogenesis, genetic damage and suppression of the immune system. Though it is not documented, it is apprehended that pesticide residue in soil could pose serious threat to soil microbes. The present investigation therefore, conducted to understand the persistent nature of carbofuran both in soil and sugarcane plant. Efforts have also been made to determine plant uptake of the aged residues of carbofuran and to assess the amount and degradation rate of residue of carbofuran in soil.

\section{Materials and Methods}

Carbofuran (Furadan 5G) was applied @ 2 kg/ha in a replicated field trial of sugarcane conducted at the Regional Sugarcane Research Station (RSRS) of BSRI, Gazipur during December
2006 to December 2007. The purity of Furadan $5 \mathrm{G}$ was tested at the pesticide analytical laboratory of BARI and was found to be $100 \%$ pure. Soil $(500 \mathrm{~g})$ and sugarcane samples $(500 \mathrm{~g})$ from replicated plots were collected at $0,3,7$, 15, 30, 60 and 90 days after application (DAA). The standard of carbofuran was obtained from Sigma-Aldrich Laborchemikalien, Gmbh P.O. Box-100262, D-30918, Seelze, Germany via Bangladesh Scientific Pvt. 1td., Dhaka, Bangladesh. The purity of this standard was above 99.6 percent.

\subsection{Extraction, separation and clean-up of carbofuran}

The methodology prescribed by William and George (2005) with necessary modification was adopted for extraction, separation and clean-up of the sample.

Field collected sugarcane and soil samples $(\geq 250$ g) were taken for extraction. Sugarcane sample was grounded thoroughly with the meat grinder (Handmixer M-122, Bamix, Switzerland) but for soil this was not needed. For both, a sub sample of $20 \mathrm{~g}$ was taken into a wide mouth jar. Then $100 \mathrm{ml}$ of methanol was added to it. Sodium sulphate $\left(\mathrm{Na}_{2} \mathrm{SO}_{4}\right)$ was also added with the sample until water was removed from the sample. The mixture was then macerated with high-speed homogenizer (Ultraturax, IKA T18 basic, Germany) for 2 minutes. The homogenized material was then poured into 250 $\mathrm{ml}$ conical flask and placed into shaker (Orbital Shaking Incubator, Rexmed, Sweden) for 2-3 hours continuous shaking. After shaking, the slurry was filtered through a Buchner funnel with suction. The flask and filter cakes were rinsed with 8-10 $\mathrm{ml}$ of methanol each.

The filtrate was then transferred into $250 \mathrm{ml}$ round bottom flask and was dried to $5-7 \mathrm{ml}$ by evaporation using a rotary vacuum evaporator (Laborota-4001, Heidolph, Germany). The concentrated filtrate was then transferred into $500 \mathrm{ml}$ separatory funnel making $10 \mathrm{ml}$ volume with methanol. Around $20 \mathrm{ml}$ hexane was added with $10 \mathrm{ml}$ filtrate to the separatory funnel and 
was shaken vigorously for 3-5 minutes and elluted into vial after keeping undisturbed for 3-5 minutes. The ellute was then centrifuged at 1200 rpm for 5 minutes (Laboratory Centrifuges, Sigma-3K30, Germany). After centrifuge, the supernatant was collected for injection.

\subsection{Detection and quantification of carbofuran residue in samples}

The residue was measured by GC-MS QP2010 (Shimadzu) with EI mode. The capillary column condition was AT-1, length $30 \mathrm{~m}$, ID $0.25 \mathrm{~mm}$ and film thickness $0.25 \mu \mathrm{m}$. Helium was used as carrier and make up gas. The parameters set for GC and MS are given below:

\section{[GC-2010]:}

Column Oven Temp. - 50.0 $0^{\circ}$, Injection Temp. $250.00^{\circ} \mathrm{C}$, Injection Mode- Splitless

Flow Control Mode - Linear Velocity.

Oven Temp. Program:

$\begin{array}{ccc}\text { Rate } & \text { Temperature }\left({ }^{\circ} \mathrm{C}\right) & \text { Hold Time }(\mathrm{min}) \\ - & 50.0 & 1.00 \\ 20.0 & 140.0 & 0.00 \\ 10.0 & 220.0 & 0.00\end{array}$

\section{[MS-QP2010]:}

Ion Source Temp. - $200.00^{\circ} \mathrm{C}$, Interface Temp. $280.00^{\circ} \mathrm{C}$, Solvent Cut Time - $5.00 \mathrm{~min}$, Ionization Mode- EI, Start Time- $5.00 \mathrm{~min}$, End Time - $13.50 \mathrm{~min}$, ACQ Mode- SIM

Ch1 $-\mathrm{m} / \mathrm{z}-164.00$

A standard calibration curve was obtained by injecting different concentrations of standard carbofuran solution. The injected volume of supernatant was 1ųl. Each peak was characterized by its retention time. Sample results were quantitated in ppm automatically by the GC software, which represented the concentration of the final volume injected and from this, concentration in the sample was obtained by back calculation. The sensitivity of the equipment for carbofuran detection was 1 $\mathrm{ppb}$ as the limit of detection (LOD).

\section{Results and Discussion}

The results of the analysis of carbofuran in soil samples have been summarized in Table 1. The results revealed that significant amount of carbofuran residue was found in soil sample even at 90 DAA. The quantities of residue were 24.84, $3.33,2.12$ and $0.59 \mathrm{ppm}$ at $0,3,7$ and 15 DAA, respectively. While soil samples of 30,60 and 90 DAA contained $0.035,0.02$ and 0.005 ppm, respectively.

Table 1. Quantity of carbofuran residue estimated from soil samples.

\begin{tabular}{ccccccc}
\hline $\begin{array}{c}\text { Days after } \\
\text { application } \\
(\mathrm{DAA})\end{array}$ & $\begin{array}{c}\text { Application } \\
\text { rate }(\mathrm{kg} / \mathrm{ha})\end{array}$ & $\begin{array}{c}\text { Sample } \\
\text { weight }(\mathrm{g})\end{array}$ & $\begin{array}{c}\text { Total volume } \\
\text { prepared }(\mathrm{ml})\end{array}$ & $\begin{array}{c}\text { Injected } \\
\text { volume }(\mu \mathrm{l})\end{array}$ & $\begin{array}{c}\text { Conc. obtained } \\
\text { in }\end{array}$ & $\begin{array}{c}\text { Residue of } \\
(\mathrm{ppm})\end{array}$ \\
\hline 0 & 2 & 20 & 10 & 2 & 49.69 & 24.84 \\
3 & 2 & 20 & 10 & 2 & 6.63 & 3.32 \\
7 & 2 & 20 & 10 & 2 & 4.24 & 2.12 \\
15 & 2 & 20 & 10 & 2 & 1.18 & 0.59 \\
30 & 2 & 20 & 10 & 2 & 0.07 & 0.035 \\
60 & 2 & 20 & 10 & 2 & 0.04 & 0.02 \\
90 & 2 & 20 & 10 & 2 & 0.01 & 0.005 \\
\hline
\end{tabular}


Table 2: Quantity of carbofuran residue estimated from sugarcane samples

\begin{tabular}{ccccccc}
\hline $\begin{array}{c}\text { Days after } \\
\text { application } \\
(\mathrm{DAA})\end{array}$ & $\begin{array}{c}\text { Application } \\
\text { rate }\end{array}$ & $\begin{array}{c}\text { Sample } \\
(\mathrm{kg} / \mathrm{ha})\end{array}$ & $\begin{array}{c}\text { Total volume } \\
\text { weight } \\
(\mathrm{g})\end{array}$ & $\begin{array}{c}\text { Injected } \\
\text { prepared }(\mathrm{ml}) \text { volume }(\mu \mathrm{l})\end{array}$ & $\begin{array}{c}\text { Conc. obtained } \\
\text { in final volume } \\
(\mathrm{ppm})\end{array}$ & $\begin{array}{c}\text { Residue of } \\
\text { carbofuran in } \\
\text { sugarcane }(\mathrm{ppm})\end{array}$ \\
\hline 0 & 2 & 20 & 10 & 2 & 0.007 & 0.0035 \\
3 & 2 & 20 & 10 & 2 & 0.15 & 0.075 \\
7 & 2 & 20 & 10 & 2 & 0.07 & 0.035 \\
15 & 2 & 20 & 10 & 2 & 0.03 & 0.015 \\
30 & 2 & 20 & 10 & 2 & 0.005 & 0.0025 \\
60 & 2 & 20 & 10 & 2 & 0.004 & 0.002 \\
90 & 2 & 20 & 10 & 2 & 0.004 & 0.002 \\
\hline
\end{tabular}

This result agrees with the observation of Stanovick (1968) who observed 20 to $35 \%$ of carbofuran remaining intact after 40 days of flooding, except in a relatively acid soil $\left(\mathrm{p}^{\mathrm{H}} 4.2\right)$ from which $77 \%$ unchanged parent compound was recovered. The results of the analysis of carbofuran in sugarcane sample have been summarized in Table 2.

FAO/WHO Codex Alimentarius Commission

Recommended

MRL of carbofuran : $0.1 \mathrm{mg} / \mathrm{kg}$ crop

ADI of carbofuran : $0.01 \mathrm{mg} / \mathrm{kg}$ body weight (Anon. 1993)

Table 2 shows that carbofuran residue was found in the sugarcane plant sample even at 90 DAA. The amount of carbofuran residue found in plant samples were $0.0035,0.075,0.035,0.015$, $0.0025,0.002$ and $0.002 \mathrm{ppm}$ at $0,3,715,30$, 60 and 90 DAA, respectively. None of these amounts was above the recommended MRL for carbofuran in crop. This result agrees with the observation of Battu et al. (2000). They observed that carbofuran-derived residues were not detected in cane juice. Moreover, FAO/WHO (1979) also reported that the 26 samples of barley, sugarbeet, maize, onion, rape, carrot which were treated with carbofuran at sowing but did not find any detectable residues in any of the samples. Similar result was reported by Anon. (1977), who collected egg plants sample from three locations of Mexico to analyse for carbofuran and 3-hydroxy-carbofuran. Sampling was done after 7 and 14 days of treatment. In both sampling occasions no residue was detected.

In the present study, the carbofuran residue in plant sample at 0 DAA was $0.0035 \mathrm{ppm}$, which is much lower than those obtained from samples of 3 and 15 DAA (0.075 and 0.015 ppm). This might be attributed to the reason that carbofuran needed time to be adequately up taken by the plant after its application. Deuel (1975) reported that carbofuran required 96 hours to be up taken by plants. Two supervised trials were carried out in South Africa in which $3 \mathrm{~kg}$ ai/ha (registered dosage) and $4.5 \mathrm{~kg}$ ai/ha were applied. The residue in sugarcane was lower than limit of determination $(0.2 \mathrm{mg} / \mathrm{kg})$ in both experiments (Anon. 1979).

\subsection{Trend of degradation}

The trends of degradation of carbofuran residue in soil and plant are shown in Figure 1. Figure 1 shows that carbofuran residue in soil degraded steadily up to 15 DAA (86.63-97.62\%) but later the rate of degradation was negligible. In case of plant samples, degradation was found to be $53.33 \%$ at 7 DAA, which went up to $80 \%$ at 15 DAA. From 30 to 90 DAA, the residue degradation ranged from 96.00 to $97.33 \%$. Lack of available information related to the carbofuran degradation limits the results to be discussed. 


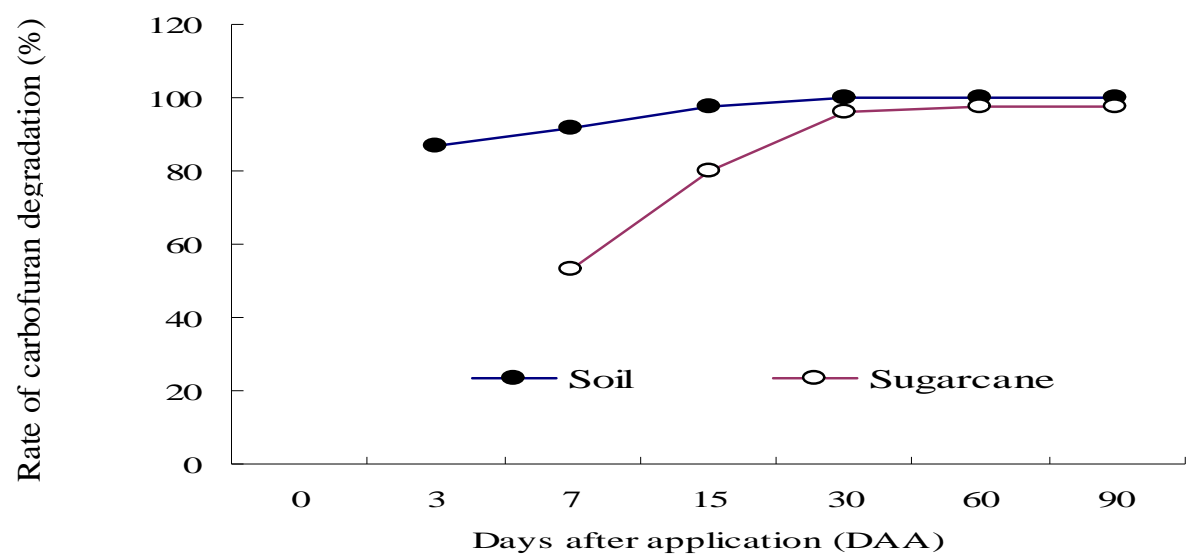

Fig. 1. The trend of carbofuran degradation in soil and sugarcane

\section{Conclusions}

Protocols for the determination of carbofuran residue from soil and plant samples have been developed. Carbofuran residues were found to be present in soil and plant sample up to 90 DAA. As higher amount of carbofuran residue remained in the soil up to $30 \mathrm{DAA}$, the future research should be conducted on its impact on soil microbes.

\section{References}

Anonymous, 2007. Bangladesh Crop Protection Association sales report 2007, Dhaka, Bangladesh.

Anonymous, 1996. List of Registered Pesticides for Agriculture and Public health. Plant Protection Wing, Department of Agriculture Extension, Khamarbari, Dhaka-1215, Bangladesh.

Anonymous. 1993. Codex Alimentarious, Pesticide Residues in Food, Vol. 2, Joint FAO/WHO Standards Program, FAO, Rome, Italy, p.86.

Anonymous, 1979. Information submitted by Country Representative, South Africa on the Joint meeting of the FAO Panel of Experts on Pesticide Residues in Food and the Environment and the WHO Expert Group on Pesticide Residues, Geneva, 3-12 December 1979

Anonymous, 1977. FMC Corporation's Unpublished Reports: No.M-4049. Carbofuran and 3-hydroxycarbofuran Residue Analysis in Mexican Egg plant.

Ashworth, R. J and Sheets, T. J. 1972. Metabolism of carbofuran in tobacco. Journal of Agricultural and Food Chemistry, 20: 407-412.

Battu, R., Kalra, R L and Dhillon, R S. 2000. Estimation of residues of carbofuran and its metabolites in sugarcane and soil by derivatization with 1-fluoro-2, 4dinitrobenzene and gas chromatography with nitrogen-phosphorus detection. Journal of AOAC International, 83(3): 569-78

Caro, J. H., Freeman, H. P., Glotfelty, D. E., Turner, B. C., Edwards, W. H. 1973. Dissipation of soil-incorporated carbofuran in the field. Journal of Agricultural and Food Chemistry, 21: 1010-1015. 
Deuel, L. E., Jr. 1975. Residue levels of propanil, molinate, carbofuran, carbaryl and their respective metabolises in rice paddy water. Diss. Abstr. Int. B, 36: 1997-1998.

FAO/WHO, 1979. Pesticide Residues in Food. Joint meeting of the FAO panel of experts on pesticide residues and WHO experts group on pesticide residues. Geneva, 3-12 December 1979.

Getzin, L. W. 1973. Persistence and degradation of carbofuran in soil. Environmental Entomology, 2: 461-467.

IRRI. 1975. Control and management of insects. IRRI Annual Report, 1974; International Rice Research Institute: Los Banos, Philippines.

Maclntyre, A. N. N., Allison, N. and Penman, D. R. 1989. Insecticides: issues and options for New Zealand Ministry of the Environment, Wellington, New Zealand.

Mansingh, A. Robinson, D. E. Walker N., and Thomas, C., 1996. Distribution, fate and effects of pesticides in tropical marine environment, Presented at the third IAEA-MEL Res. Coordination meeting heredia, Costa Rica, 9-13 September.
Mullie, W. C., Verwey, P. J., Gerends, A. G., Sene, F., Koeman, J. H. and Everts, J. W. 2005. The impact of furadan $3 \mathrm{G}$ (carbofuran) applications on aquatic macroinvertabrates in irrigated rice in Senegal. Journal of Archives of Environmental Contamination and Toxicology, 20 (2): 177-182

Stanovick, R. P. 1968. Metabolism of Carbofuran in Soil. I. Quantitative and qualitative determination of radioactive carbofuran and its metabolites in soil. FMC Corporation, Report No. M. 2303, 1968.

Talekar N. S., Lee, E. M., Sun, L. T.1977a. Absorption and translocation of soil and foliar applied ${ }^{14} \mathrm{C}$-carbofuran and ${ }^{14} \mathrm{C}$ phorate in soybean and mung bean seeds. Journal of Economic Entomology, 70: 685-688.

Talekar, N. S., Sun, L. T., Lee, E. M., Chen, J. S. 1977b. Persistence of some insecticides in subtropical soil. Journal of Agricultural and Food Chemistry, 25: 384-352.

William, H and George, W. L, Jr. 2005. Official Methods of Analysis of AOAC International, 18th Edition, AOAC International, Gaithersburg, USA, Chapter 10, 41 p. 